\title{
The evaluation of ectopic pregnancy prevalence and its causes from 2006 to 2018 in Sarem hospital
}

\section{ARTICLE INFO \\ Article Type \\ Original Article \\ Authors \\ AboTaleb Saremi ${ }^{1}$, iD MD * \\ Khadijeh Abadian ${ }^{1}, \mathrm{PhD}$ \\ Masoumeh Halalian ${ }^{1}$, MSc \\ Maryam Mahmoudinia Meymand ${ }^{2}, \mathrm{PhD}$ \\ Javad Amini Mahabadi 1,3, iD ${ }_{\mathrm{PhD}}$ \\ 1 Sarem Fertility \& Infertility Research Center (SAFIR), Sarem Women's Hospital, Iran University of Medical Sciences (IUMS), \\ Tehran, Iran \\ 2 Sarem Cell Research Center (SCRC), Sarem Women's Hospital, Iran University of Medical Sciences (IUMS), Tehran, Iran. \\ $3 \mathrm{PhD}$ of reproductive biology, Gametogenesis Research Center, Kashan University of Medical Sciences, Kashan, Iran.}

\section{*Corresponding Author}

Address: Sarem Women Hospital, Basij Square, Phase 3, EkbatanTown, Tehran, Iran. Postal code: 1396956111

Phone: +98 (21) 44670888 Fax: +98 (21) 44670432

Dr.saremi@sarem.org

\section{ABSTRACT}

Introduction: Ectopic pregnancy refers to placental implantation in a location other than the uterine cavity and is the most common cause of death in pregnant women in pregnancy first trimester. Regarding to this important topic and its complications, the present study was designed and conducted to evaluate the prevalence of ectopic pregnancy and its risk factors in Sarem hospital.

Methods: This is a retrospective descriptive cross-sectional study in which 149 patients' cases referred to Sarem hospital were studied from 2006 to 2018 and obtained data was analyzed by SPSS software 22 version.

Results: The results of this study based on the history of ectopic pregnancy disease demonstrated that out of samples total number, pregnancy gravid was reported $40.7 \%$ in first pregnancy, 59.3\% in second pregnancy and abortion history $9.4 \%$. In this research, the patients did not mention an abortion history and infertility; and also, most of them had no way to contraception. Of evaluated patients, a history of uterine tubal surgery was $4.7 \%$ and surgeon history on abdominal and pelvic was $47 \%$. Tubes had the most of conflict point and right direction had the most of conflict side. Clinical symptoms of patients included abdominal pain and vaginal bleeding, and the main treatment method of them was laparoscopy.

Conclusion: regarding to obtained results, it seems abdominal or pelvic surgery can lead to complications such as ectopic pregnancy and this point can be considered in cesarean section.

Keywords: Ectopic pregnancy; Prevalence; Risk factors; Hospital. 
جراحى شكمى يا لكنى داشتند. لوله ها بيشترين محل دركيرى و سمت

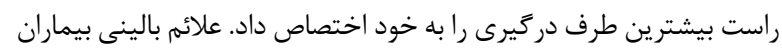

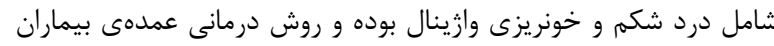
نيز لإياراسكويى بود. نتيجه

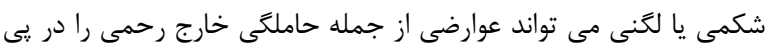

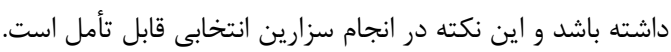

كليد وازمها: حاملكى خارج رحمى؛ شيوع؛ عوامل خطر؛ بيمارستان.

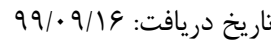

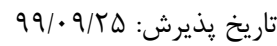

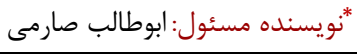

مقدمه

حاملكى خارج رحمى، به لانه زَينى جفت در محلى غير از حفره رحم

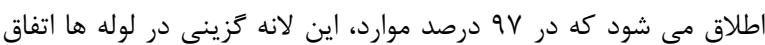

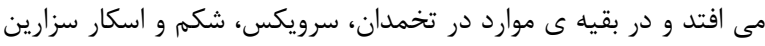

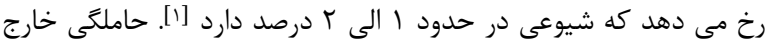

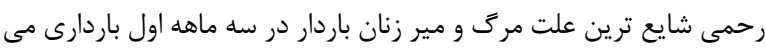

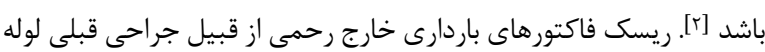

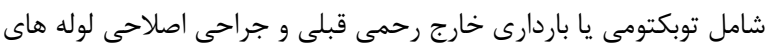

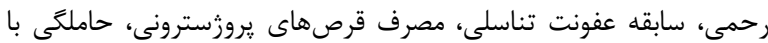

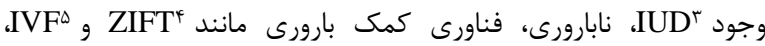

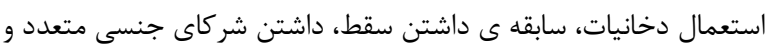

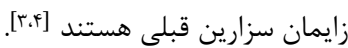

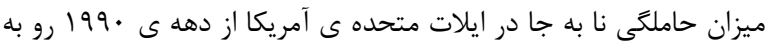

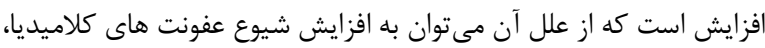

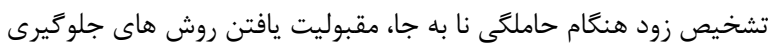

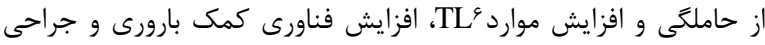

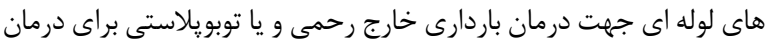

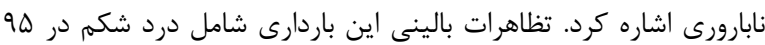

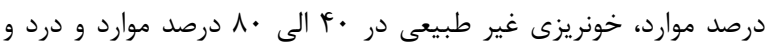

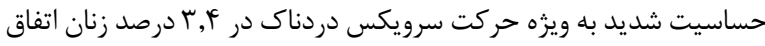
مى افتد [ه]. روش هاى تشخيصى نيز شامل اندازهيرى تئرى تيتراز

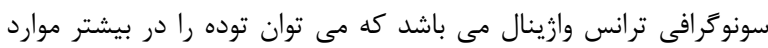

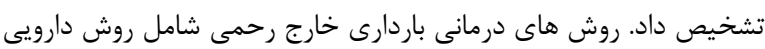

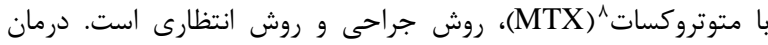

In vitro fertilization Tubal ligation Beta Human chorionic gonadotropin Methotrexate

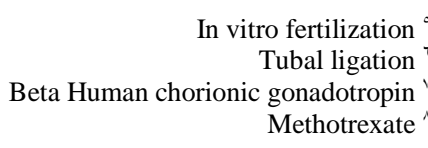

بررسى شيوع حاملكَى خارج رحمى و

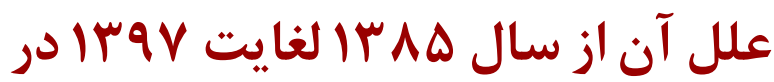
بيمارستان فوق تخصصى صارم

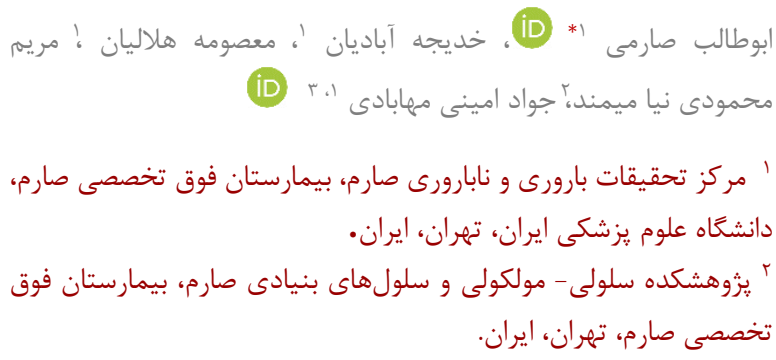
r دكترى تخصصى بيولوزى توليدمثل، مركز تحقيقات كامتوزنزيس دانشعاه علوم يزشكى كاشان، كاشان، ايران.

جكيده

مقدمه: حاملكى خارج رحمى به لانه زَينى جفت در محلى غير از حفره رحم اطلاق مى شود و شايع ترين علت مرى و مير زنان باردار در سه ماهـ ماهده

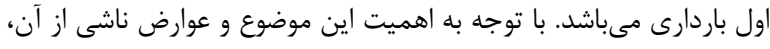

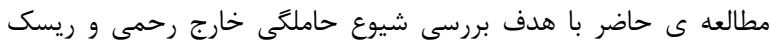
فاكتورهاى مربوط به آن در بيمارستان فوق تخصصى برى صارم طرح ريزى و و اجرا كرديد. روش: اين يزوهش يك مطالعه ى توصيفى-مقطعى حذشتهنكر است كه

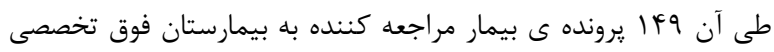

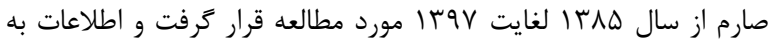
دست آمده با نرم افزار SPSS ورثن كال هار تجزيه و و تحليل شدند.

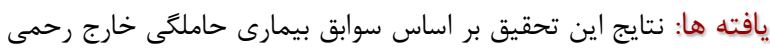

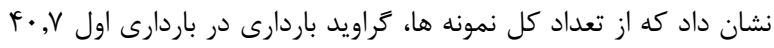

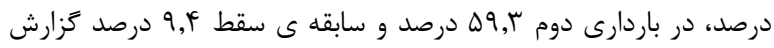

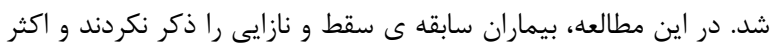

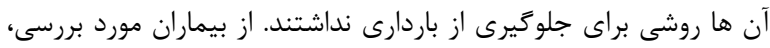

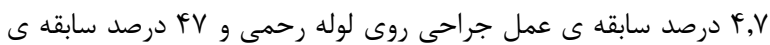

Intrauterine device Zygote intra fallopian transfer

دانشنامه صارم در طب بارورى 
جدول ا: ميزان فراوانى يارامترهاى مختلف بر اساس سوابق بيمارى حاملكى خارج

\begin{tabular}{|c|c|c|c|c|}
\hline فراوانى & فراوانى & & & متغيرها \\
\hline$f \cdot, \mathrm{V}$ & $\Delta 9$ & & باردارى اول & \multirow{2}{*}{ كراويد باردارى } \\
\hline$\Delta q, \Gamma$ & १. & \multicolumn{2}{|c|}{ باردارى دوم و بيشتر } & \\
\hline 9,4 & if & \multicolumn{2}{|r|}{ دارد } & \multirow{2}{*}{ سابقه ى سقط } \\
\hline $9 \cdot, 9$ & $1 T \Delta$ & \multicolumn{2}{|r|}{ ندارد } & \\
\hline 1,54 & $r$ & قرص | قرص & \multirow{3}{*}{ مارد } & \multirow{4}{*}{ جلوكيرى از باردارى } \\
\hline$\Delta, r V$ & $\Lambda$ & كاندوم & & \\
\hline $19, \mathrm{Y9}$ & $r \Delta$ & طبيعى & & \\
\hline$v 9, \Delta$ & $11 f$ & \multicolumn{2}{|r|}{ ندارد } & \\
\hline 9,4 & if & \multicolumn{2}{|r|}{ دارد } & \multirow{2}{*}{ سابقه ى نازايى } \\
\hline $9 \cdot$, & 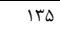 & & ندارد & \\
\hline$f, r$ & v & دارد & \multirow{2}{*}{ لوله رحمى } & \multirow{4}{*}{ سابقه ى جراحى } \\
\hline $9 \Delta, r$ & IfF & ندارد & & \\
\hline iv & v. & دارد & \multirow{2}{*}{ شكمى يا لكنى } & \\
\hline$\Delta r$ & va & ندارد & & \\
\hline .99 & 1 & & ديابت & \multirow{4}{*}{ بيمارى زمينه اى } \\
\hline$r, Y$ & f & & قلبى & \\
\hline 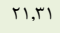 & rT & & ساير & \\
\hline$v_{\Delta, r}$ & $11 \%$ & & ندارد & \\
\hline
\end{tabular}

جدول شماره r: ميزان فراوانى بر اساس محل، سمت دركير شده و علائم بالينى

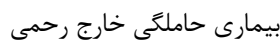

\begin{tabular}{|c|c|c|c|}
\hline فراوانى & فراوانى & & متغيرها \\
\hline$\checkmark 1, \Lambda$ & $1 \cdot v$ & لوله & \multirow{5}{*}{ محل دركيرى } \\
\hline$f, \cdot f$ & 9 & كورنه & \\
\hline 19,49 & rq & تخمدان & \\
\hline$r, Y$ & i & اسكار .سزارين & \\
\hline r & $r$ & لوله. تخمدان & \\
\hline$r v, \Delta$ & $\Delta \varphi$ & جي & \multirow{2}{*}{ طرف دركيرى } \\
\hline sT,Q & 9 & راست & \\
\hline$\Delta \Lambda, r q$ & Av & درد شكم & \multirow{3}{*}{ علائم بالينى } \\
\hline$|f, 1|$ & ri & خونريزى غيرطبيعى واثينال & \\
\hline$r v, \Delta$ & i) & درد شكم و خونريزى وارينال & \\
\hline
\end{tabular}

همان طور كه در جدول r نشان داده شد، بيشترين درصد محل دركيرى

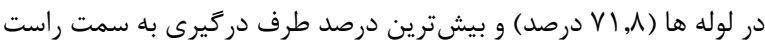

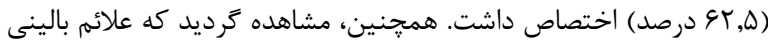
q

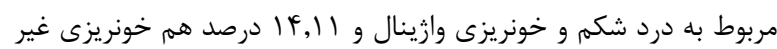

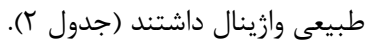

انتظارى نيز براى بيمارانى با علائم ناجيز، پايدار از نظر بالينى و نامشخص

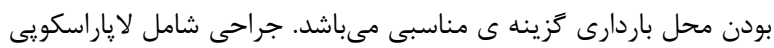

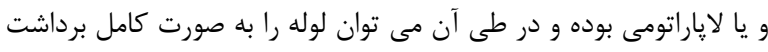

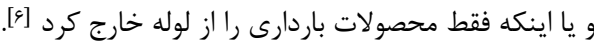

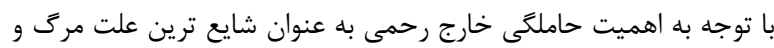

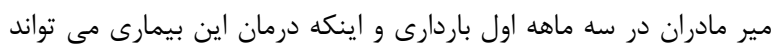

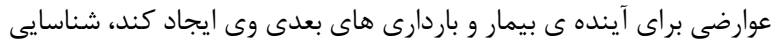

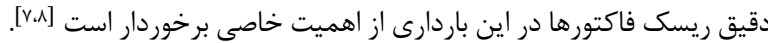

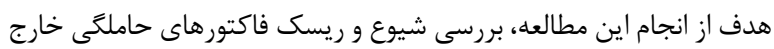

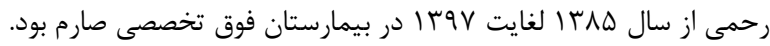

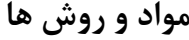

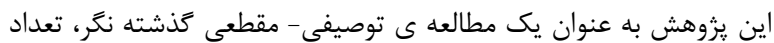

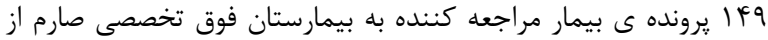

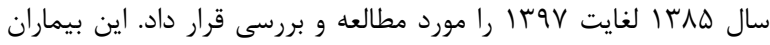

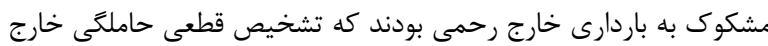

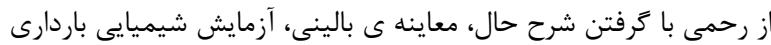

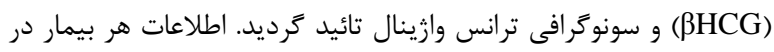
يرسش نامهاى كه تنظيم شده بود، وارد شد. در يرسشنامه، اطلاعات

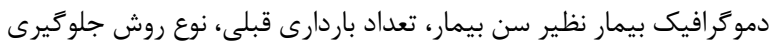

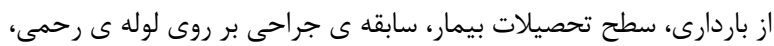

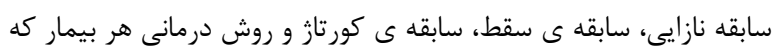

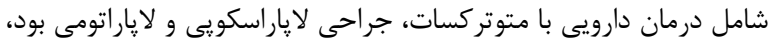

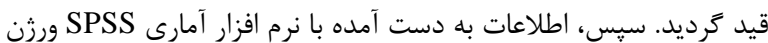

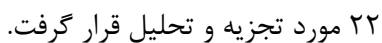

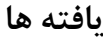

بر اساس بررسى هاى انجام شده و يروندههاى موجود، در بازه ي زمانى

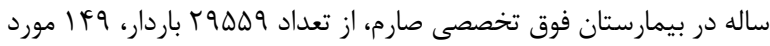

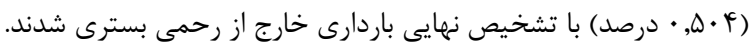

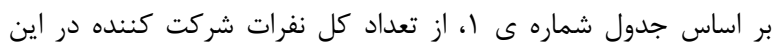

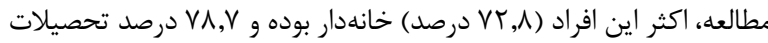

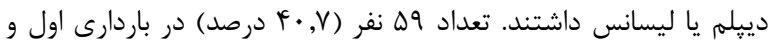

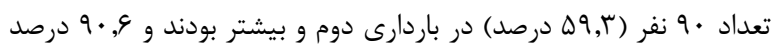

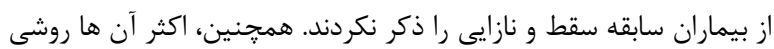

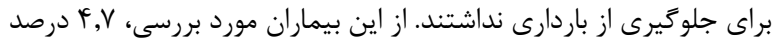

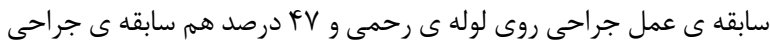

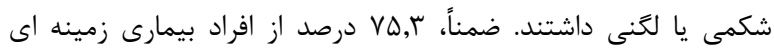

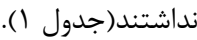


داد [-1]. با اين حال، نقشى كه اين ريسك فاكتورها در حاملگى خارج رحمى داري

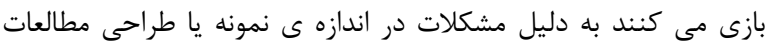

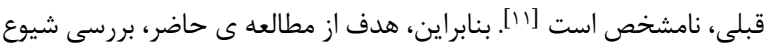

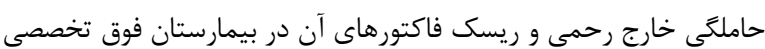

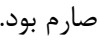
نتايج اين بررسى نشان داد كه شيوع باردارى خارج رحمى در جامعه ى

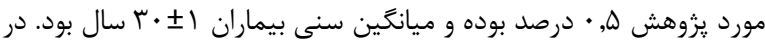

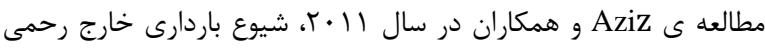
هA

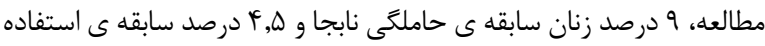

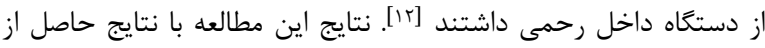

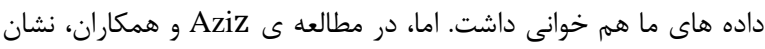

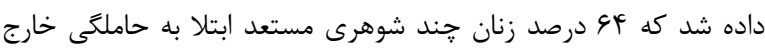

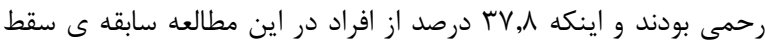

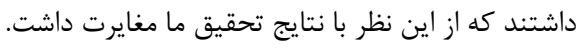

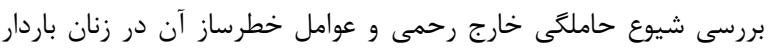

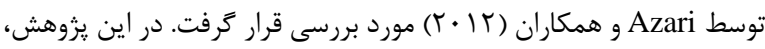

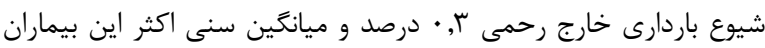

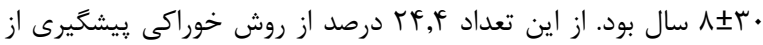

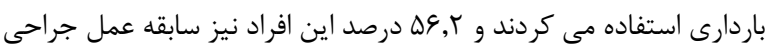

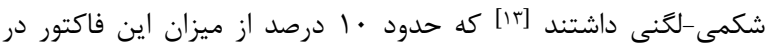

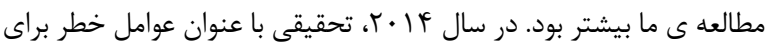

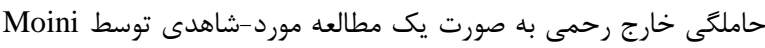

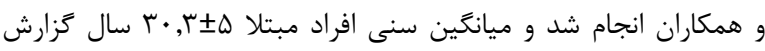

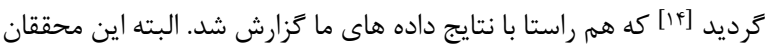

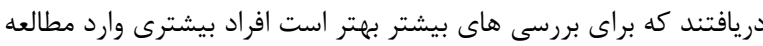
شوند.

بر طبق نتايج حاصل از يك مطالعه ى فراتحليلى، گزارش شد كه جراحى

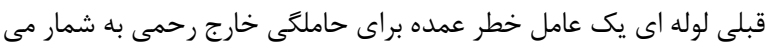

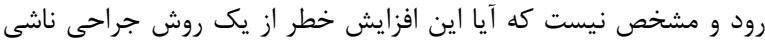

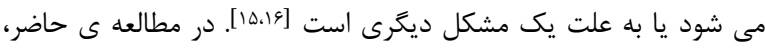

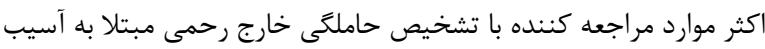

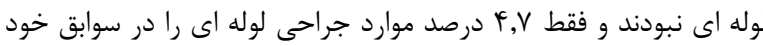
ذكر مى كردند. تحقيقى تحت عنوان ريسك فاكتورهاى اصلى در باردارى خارج خارج رحمى به

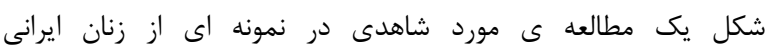

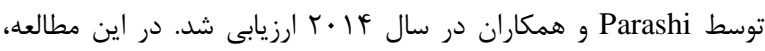

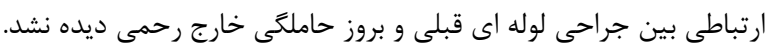

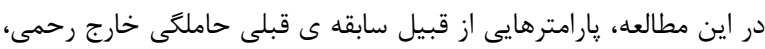

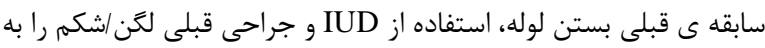

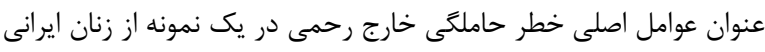

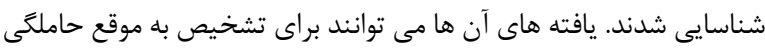

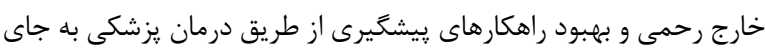

جدول بّ: ميزان فراوانى بر اساس نوع روش درمان بيمارى حاملكى خارج

رحمى

\begin{tabular}{|c|c|c|}
\hline در صد فراوانى & فراوانى & نوع روش درمانى \\
\hline$r, \cdot 1$ & r & دارويى \\
\hline$r \cdot, 1 r$ & r. & لإِاراسكويى. سالِنز كتومى \\
\hline FT,gF & $9 \Delta$ & لاياراسكويى. ساينغكوستومى \\
\hline $1 \cdot, V F^{c}$ & 19 & لاياراتومى. سالِينزكتومى \\
\hline $4, \sqrt{ })$ & 1 . & لاياراتومى. سالينگگوستومى \\
\hline $19, \mathrm{VV}$ & ra & انتظارى \\
\hline
\end{tabular}

جدول شماره ى ץ نشان داد كه روش درمانى در نظر گرفته شده براى اكثر

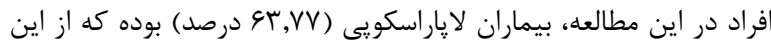

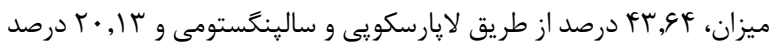

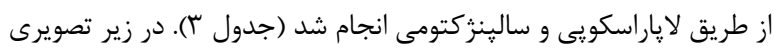

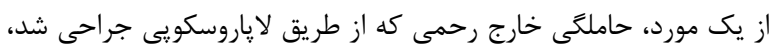

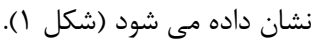

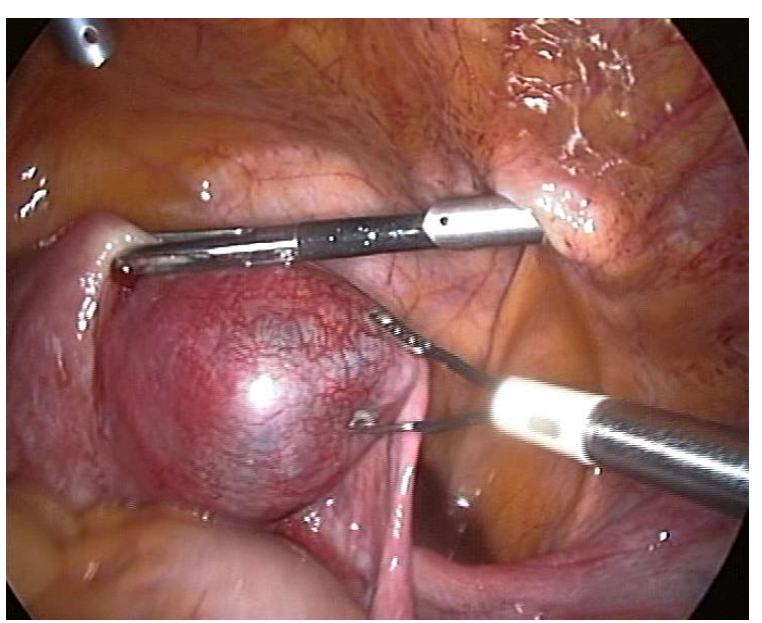

شكل ا: نماى مشاهده شده از حاملكى خارج رحمى از طريق لإياروسكوبى

حاملكَى خارج رحمى علت اصلى مرى مادران در سه ماهه اول باردارى

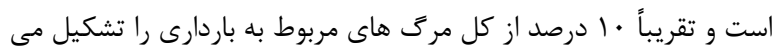

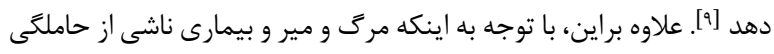

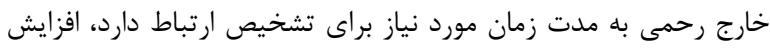

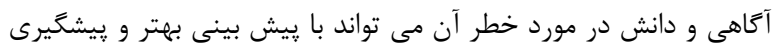

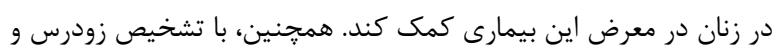

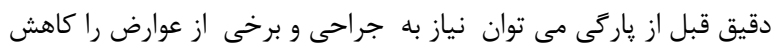




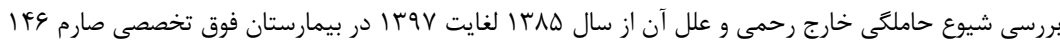

عوارضى كه شرايط فرد را براى ايجاد رخداد هايى مشابه حاملكى خارج

$$
\text { رحمى فراهم مى كند، اجتناب كرد. }
$$

\section{نتيجه كيرى}

هدف از اين مطالعه، بررسى شيوع حاملكى خارج رحمى و وريسك

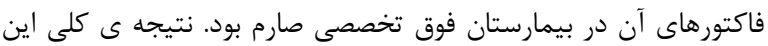

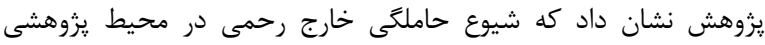

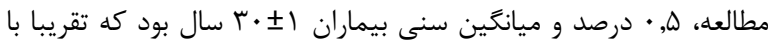

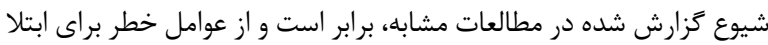

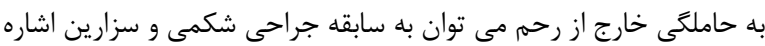

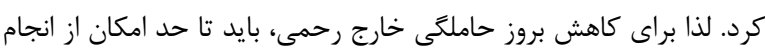

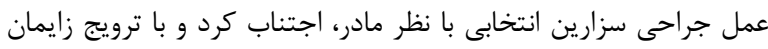

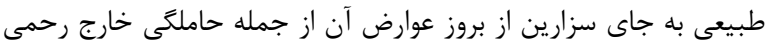
ي يشگيرى نمود.

تشكر و قدردانى

بدينوسيله از سركار خانم دكتر سميرا غفارى جهت همكارى در اين طرح

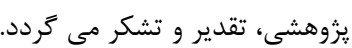

تاييديه اخلاقى اين بروهش به تائيد كميته اخلاق بيمارستان صارم رسيده است.

تعارض منافع در اين مطالعه هيج گَونه تعارض منافعى وجود نداشت.

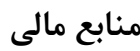

$$
\begin{aligned}
& \text { اين طرح با يشتيبانى مركز تحقيقات بارورى و نابارورى صارم انجام و تأمين } \\
& \text { مالى شده است. }
\end{aligned}
$$

منابع

1. $1 . \quad$ Stulberg DB, Cain LR, Dahlquist I, Lauderdale DS. Ectopic pregnancy rates in the Medicaid population. Am J Obstet Gynecol. 2013;208(4):274-e1.

2. Stremick JK, Couperus K, Ashworth SW. Ruptured tubal ectopic pregnancy at fifteen weeks gestational age. Clin Pract cases Emerg Med. 2019;3(1):62.

3. Skjeldestad FE, Hadgu A, Eriksson N.
درمان غيرضرورى جراحى مفيد باشد [IV]

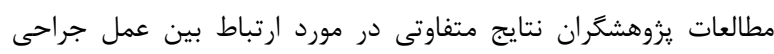

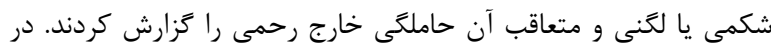

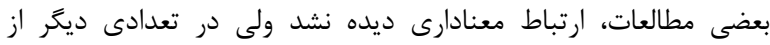

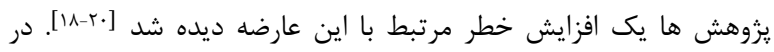

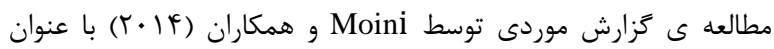

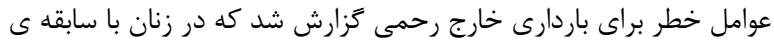

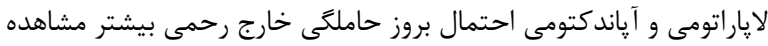

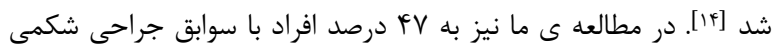

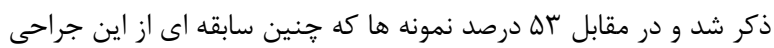

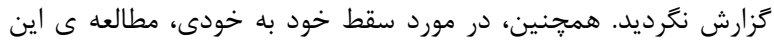

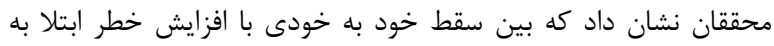

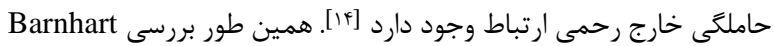

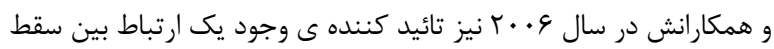

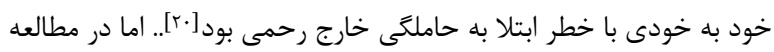

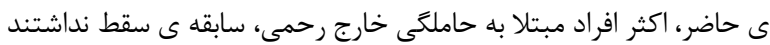
كه با نتايج آن ها هم راستا نبود.

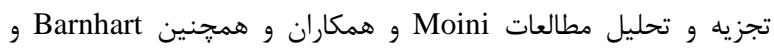

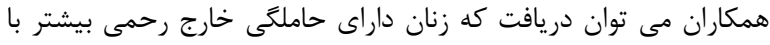

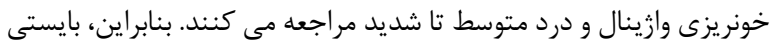

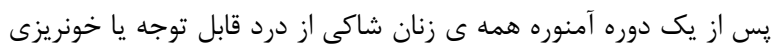

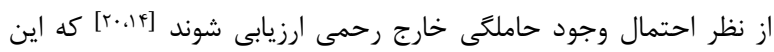

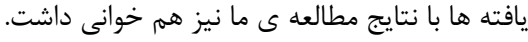

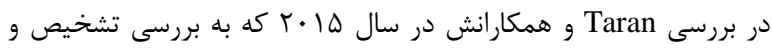

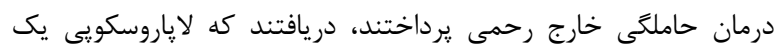

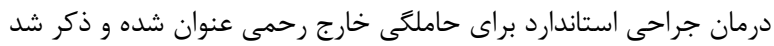

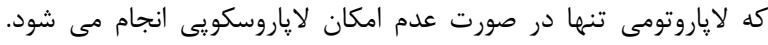

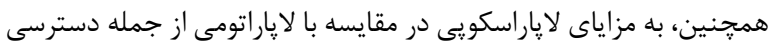

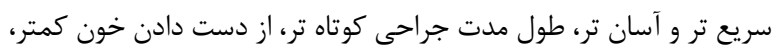

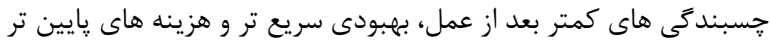

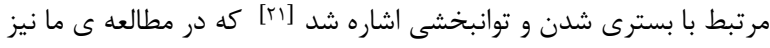

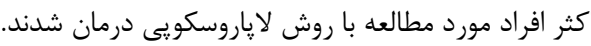

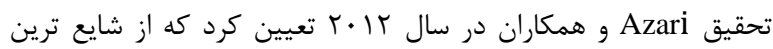

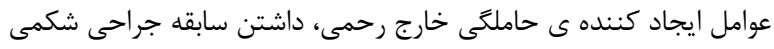

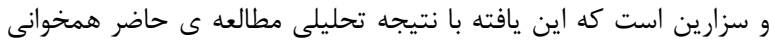

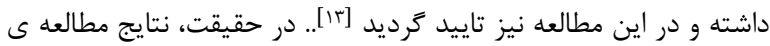

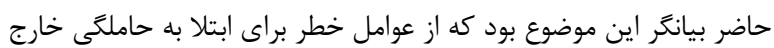

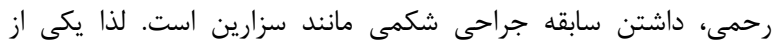

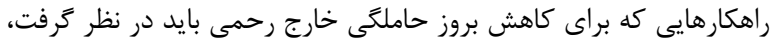

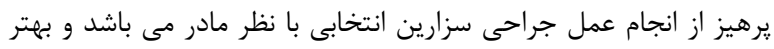

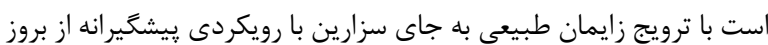


analysis. Fertil Steril. 1996;65(6):1093-9.

17. Parashi S, Moukhah S, Ashrafi M. Main risk factors for ectopic pregnancy: a case-control study in a sample of Iranian women. Int J Fertil Steril. 2014;8(2):147.

18. Li C, Zhao W-H, Zhu Q, Cao S-J, Ping H, Xi X, et al. Risk factors for ectopic pregnancy: a multi-center case-control study. BMC Pregnancy Childbirth. 2015;15(1):1-9.

19. Kaplan BC, Dart RG, Moskos M, Kuligowska E, Chun B, Hamid MA, et al. Ectopic pregnancy: prospective study with improved diagnostic accuracy. Ann Emerg Med. 1996;28(1):10-7.

20. Barnhart KT, Sammel MD, Gracia CR, Chittams J, Hummel AC, Shaunik A. Risk factors for ectopic pregnancy in women with symptomatic firsttrimester pregnancies. Fertil Steril. 2006;86(1):36-43.

21. Taran F-A, Kagan K-O, Hübner M, Hoopmann M, Wallwiener D, Brucker S. The diagnosis and treatment of ectopic pregnancy. Dtsch Arztebl Int. 2015;112(41):693.
Epidemiology of repeat ectopic pregnancy: a population-based prospective cohort study. Obstet Gynecol. 1998;91(1):129-35.

4. Bouyer J, Coste J, Shojaei T, Pouly J-L, Fernandez $\mathrm{H}$, Gerbaud L, et al. Risk factors for ectopic pregnancy: a comprehensive analysis based on a large case-control, population-based study in France. Am J Epidemiol. 2003;157(3):185-94.

5. Mikhail E, Salemi JL, Schickler R, Salihu HM, Plosker S, Imudia AN. National rates, trends and determinants of inpatient surgical management of tubal ectopic pregnancy in the United States, 1998-2011. J Obstet Gynaecol Res. 2018;44(4):730-8.

6. Van Mello NM, Mol F, Verhoeve HR, Van Wely M, Adriaanse AH, Boss EA, et al. Methotrexate or expectant management in women with an ectopic pregnancy or pregnancy of unknown location and low serum hCG concentrations? A randomized comparison. Hum Reprod. 2013;28(1):60-7.

7. Jurkovic D, Wilkinson H. Diagnosis and management of ectopic pregnancy. BMJ. 2011;342.

8. Barash JH, Buchanan EM, Hillson C. Diagnosis and management of ectopic pregnancy. Am Fam Physician. 2014;90(1):34-40.

9. Assouni Mindjah YA, Essiben F, Foumane $P$, Dohbit JS, Mboudou ET. Risk factors for ectopic pregnancy in a population of Cameroonian women: A case-control study. PLoS One. 2018;13(12):e0207699.

10. Wang X, Huang L, Yu Y, Xu S, Lai Y, Zeng W. Risk factors and clinical characteristics of recurrent ectopic pregnancy: a case-control study. J Obstet Gynaecol Res. 2020;46(7):1098-103.

11. Tsakiridis I, Giouleka S, Mamopoulos A, Athanasiadis A, Dagklis T. Diagnosis and Management of Ectopic Pregnancy: A Comparative Review of Major National Guidelines. Obstet Gynecol Surv. 2020;75(10):611-23.

12. Aziz S, Wafi BA, Swadi H Al. Frequency of ectopic pregnancy in a medical centre, Kingdom of Saudi Arabia. JPMA-Journal Pakistan Med Assoc. 2011;61(3):221.

13. Azari M, Fasih M, Mardi A. A study of ectopic pregnancy prevalence and it's risk factors among peregnant women. J Heal Care. 2012;14(1):0.

14. Moini A, Hosseini R, Jahangiri N, Shiva M, Akhoond MR. Risk factors for ectopic pregnancy: A case-control study. J Res Med Sci Off J Isfahan Univ Med Sci. 2014;19(9):844.

15. Berek JS, Longacre TA, Friedlander M. Ovarian, fallopian tube, and peritoneal cancer. Berek Novak's Gynecol 15th ed Philadelphia Lippincott Williams Wilkins. 2012;1350-427.

16. Ankum WM, Mol BWJ, Van der Veen F, Bossuyt PMM. Risk factors for ectopic pregnancy: a meta- 